\title{
Design and Development of Arduino based Automatic Soil Moisture Monitoring System for Optimum use of Water in Agricultural Fields
}

\author{
Sudip Das ${ }^{1}$, Biswamoy $\mathrm{Pal}^{2}$, Partha Das ${ }^{3}$, Milan Sasmal ${ }^{4}$, Prabuddhamoy Ghosh ${ }^{5}$
}

Assistant Professor, Department of Electrical Engineering, JIS College of Engineering, Kalyani, W.B.,India

\begin{abstract}
The research aim was to the study the intelligent soil moisture control system in agricultural green house based on Adriano Uno microcontroller automation control. This kind of intelligent soil moisture control system helps to control the moisture level of the field and supply the water if required. In this research embedding a control system into an automatic water pump controller depend upon the moisture of the soil. This system also ability to detect the level of methane gas in the green house. The intelligent soil moisture control system in agricultural green house designed in the research had wonderful effort of man-machine interface, it is very simple, cheep and convenient high degree of automation system. Not only that this system helps to prevent wastage of water. This system is a prototype, which makes this self-sufficient, watering itself from a reservoir. Solar energy is used in this system makes it more environment friendly.
\end{abstract}

Keywords-ATmega328p microcontroller, temperature sensor, methane sensor, soil moisture sensor, solar cell, DC Motor. L293D Motor Driver.

\section{INTRODUCTION}

India is a country where majority of our population are dependable on the agriculture to live their daily life. In this modern technological era poor farmers of india cannot get enough assistance from others to help them with technology and make their work easier. This project made automatic field monitoring \& controlling system that can be utilize to improve the condition of green houses. Arduino Uno microcontroller is the main controlling unit of whole system. This system performed the following task:

1. Supply water according to moisture level of soil.

2. Automatic alarming system to avoid the burning of plants by excessive temperature of atmosphere.

3. Automatic methane gas detecting system in green house.

4. Reusing process of excessive water in the field.

\section{HARDWARE REQUIREMENTS}

The basic components of our projects are ATmega328p microcontroller, solar panel, dc motor, L293D motor driver module, LM35 temperature sensor, MQ22 methane sensor.

\subsection{LM35 Temperature Sensor}

The temperature sensor is used to sense the temperature in the field and its output voltage is proportional to the centigrade. The LM35 sensors have low output impedance, linear output and precise inherent calibration makes interfacing to the control circuitry easy. It is shown in figure 1.

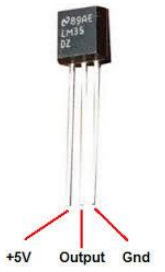

Fig.1 TEMPERATURE SENSOR

\subsection{MQ2 Methane Sensor}

It is used for gas leakage detecting (in home and industry).It can detect LPG, methane, i-butane, smoke and so on. Based on its fast response time, measurements can be taken as soon as possible and necessary actions are taken. This type of sensor is shown in figure 2. 


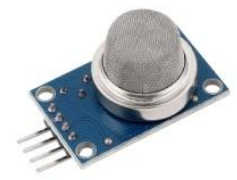

Fig.2 METHANE SENSOR

\subsection{Soil Moisture Sensor:}

The soil moisture senses the moisture content in the soil and based on the value that is showed on the display, according to the control circuit motor will be start ant it will pump the water with the help of a pump and the pumping actions will continue till it fulfills the conditions. With the help of this sensor which is shown in figure 3 we can find whether the soil is dry or wet. A local circuit connection is shown in figure 4.

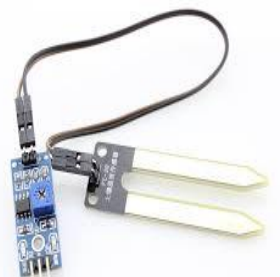

Fig.3 SOIL MOISTURE SENSOR

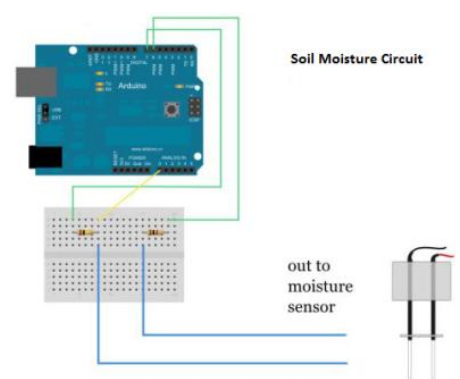

Fig.4 SoIL MoISTURE Circuit

\subsection{Motor \& Drive Circuit:}

There are two dc motors used in this project. The $1^{\text {st }} \mathrm{dc}$ motor works only to help the pump to pump water into the soil when the moisture level of the soil shown in the monitor is below the rated level that has been set in microcontroller program. And the $2^{\text {nd }} \mathrm{dc}$ motor works only in case when rain fall and execs water was suction by that motor. Stored in a supply tank for reusing the store water. The fig.5 shows the dc motor which used in this system. In this project L293D used for conversion binary data to mechanical data. The driver circuit as shown in figure 6 .

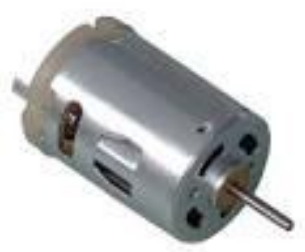

FIG.5 DC MOTOR

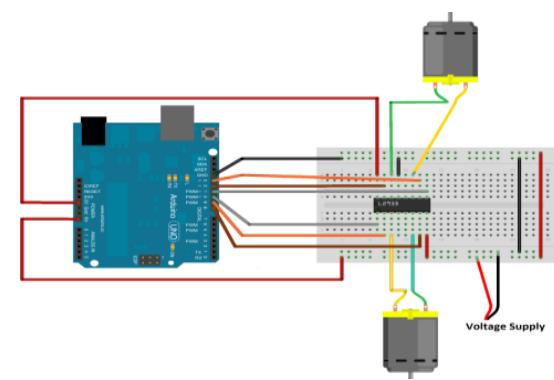

Fig.6 Motor DRIVER CiRCUIT

\subsection{Arduino Uno}

The Arduino Uno is a microcontroller is shown in figure 7 that has 14 digital input-output pins. 6 analog inputs, $16 \mathrm{MHz}$ ceramic resonator. It is connected with a computer with the help of a USB cable or powers it with ac to dc adapter or a battery for power supply.

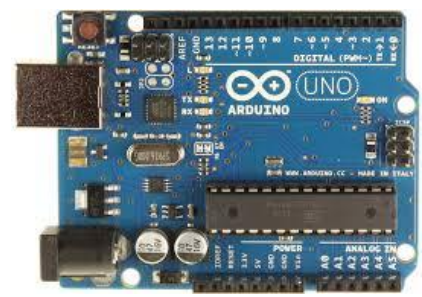

Fig.7 ARduino UnO MiCROCONTROLLER 


\section{OBJECTIVES}

In non conventional energy era, solar energy is one of the most effective energy sources, so solar cells are used to power our circuit .The main objective of this project was to design a greenhouse monitoring system that is be highly reliable and is useful for harvesting crops. Our project mainly focuses on the control of parameters such as-temperature, methane quantity, soil moisture .The block diagram of the greenhouse monitoring system has been shown in Figure 8.

\section{BLOCK DIAGRAM}

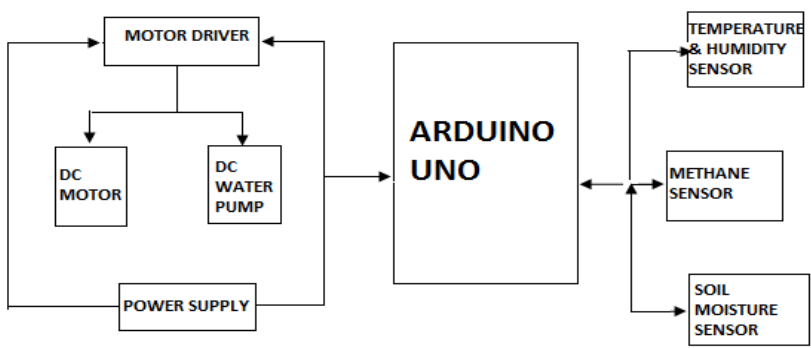

FIG. 8 BLOCK DIAGRAM

\section{FLOW CHART}

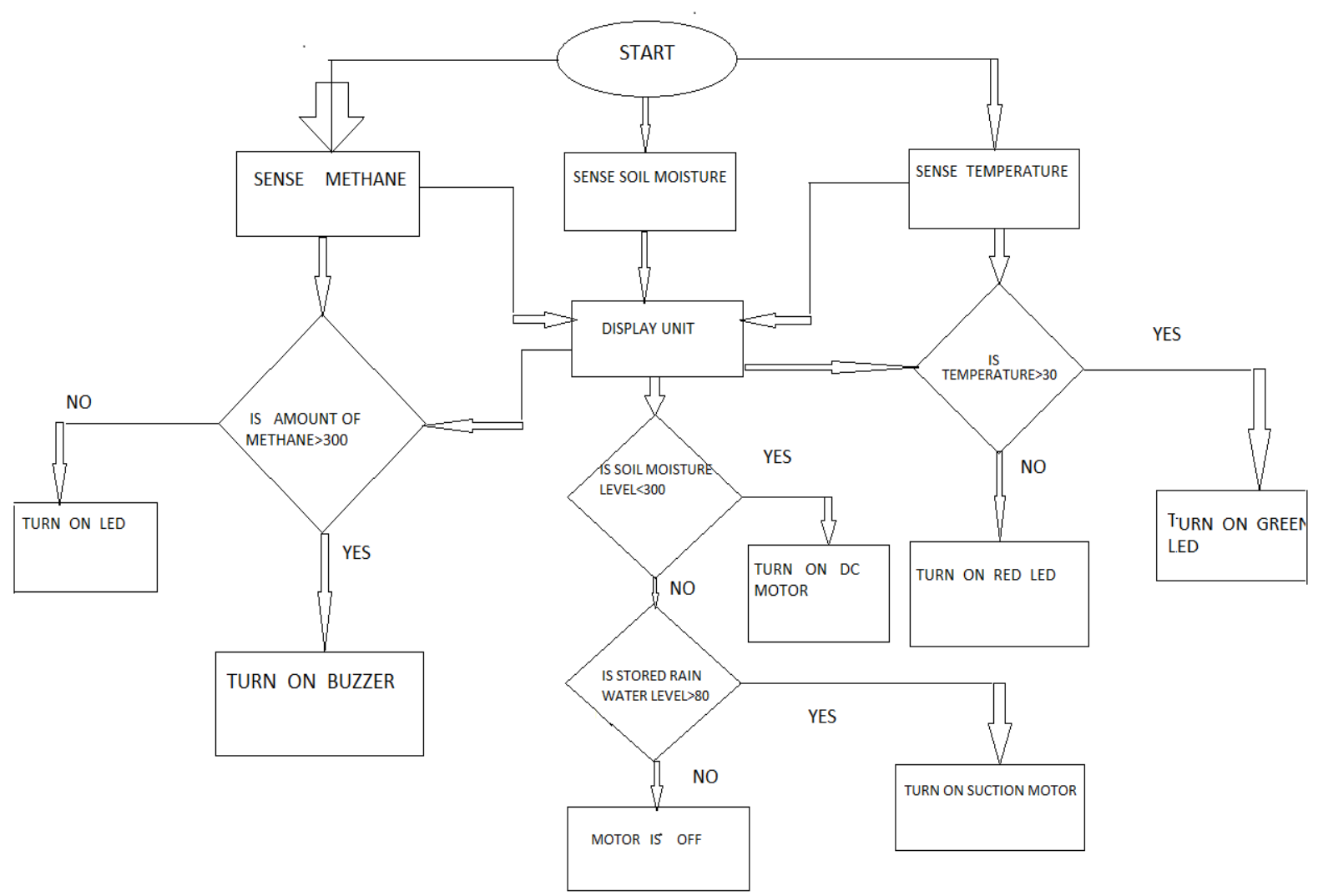

Fig. 9 FLOW CHART

\section{MeThodology}

In case of hardware implementation the sensors -temperature sensor, soil moisture sensor, methane sensor were connected with the ATmega328p microcontroller and was connected with the microcontroller with the motor driver module and the power was supplied with the help of a solar panel. Flow chart of this entire project has been shown in Figure 9. The sensors sensed the parameters such as temperature, methane quantity, soil moisture and the microcontroller sensed the values from them and was displayed onto the LCD screen and accordingly the control actions were done that were needed. In case of temperature sensor, if temperature is increased then the greenhouse door was closed manually and if the moisture 
quantity of the sand is less than the desired value then accordingly motor was on and vice-versa. Schematic diagram of this project is shown in figure 10 .

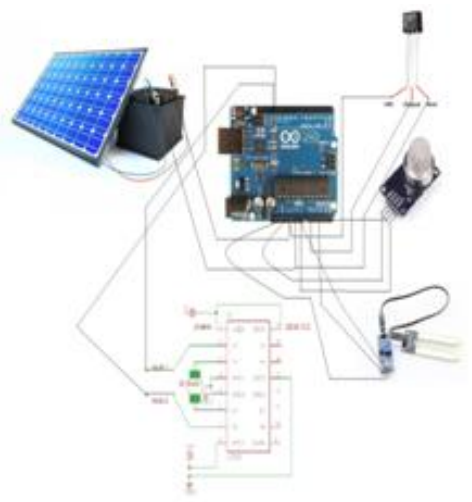

\section{Fig.10 SCHEMATIC DiAgRAM}

VII. RESULT

All Sensors determined the soil moisture level, Humidity, Temperature, Methane gas at the root zone. Arduino Micro controller should get sensor data in per minute. Micro controller should record \& analyze all the data and take correct action. Soil moisture sensor takes an important role in an agricultural system controller. Soil moisture level set as per based on plant specification, soil type, seasonal rainfall. Arduino microcontroller should upload that observed data in every hour and supply water flow as per requirements.

Efficient results have been obtained from the following project. Table 1 shows the recorded data at field in several days. The hardware implementations have been successful and they are reliable and the sensors that we are using are giving good results and performing to the expectations.

TABLE 1

RECORDED DATA

\begin{tabular}{|c|c|c|c|c|}
\hline $\begin{array}{c}\text { Date \& Time } \\
\text { (11.30am) }\end{array}$ & $\begin{array}{c}\text { Atmospheric } \\
\text { Temperature }\end{array}$ & $\begin{array}{c}\text { Atmosphere } \\
\text { Humidity(\%) }\end{array}$ & Soil Temperature & $\begin{array}{c}\text { Soil Moisture } \\
\text { (\%) }\end{array}$ \\
\hline $20 / 04 / 2017$ & 29 & 55 & 28 & 32 \\
\hline $21 / 04 / 2017$ & 28 & 52 & 27 & 30 \\
\hline $22 / 04 / 2017$ & 30 & 67 & 29 & 28 \\
\hline $23 / 04 / 2017$ & 32 & 75 & 31 & 26 \\
\hline $24 / 04 / 2017$ & 33 & 81 & 32 & 21 \\
\hline
\end{tabular}

\section{APPLICATION AND FUTURE SCHOPE}

The application of greenhouse monitoring system in agricultural aspect is immense. The automated greenhouse monitoring system will help to reduce the efforts and workloads of human and will be helping to produce plants at the absolute parameters they want them to plant and it will reduce the error. Its ability to control appliances through internet may be integrated for further case. In near future the system can be made $100 \%$ autonomous so that it can take all the necessary actions and will result in a effective plant growth. And if we use the bi-directional motor pump, but the rest of the project set up will be same, in that case the system will be cost effective.

\section{CONClusion}

This project of greenhouse monitoring system has been developed based on the arduino Uno. The microcontroller circuit has been developed with less number of components and is highly reliable. After verifying the data that was shown in got in monitor, assured about the success of the project. Presence of each module has been systematic out and placed carefully, thus contributing to the best working of the every unit. Thus, the Arduino Based Automatic soil moisture monitoring system has been designed and tested successfully. Project snapshots are shown in figure 11. 

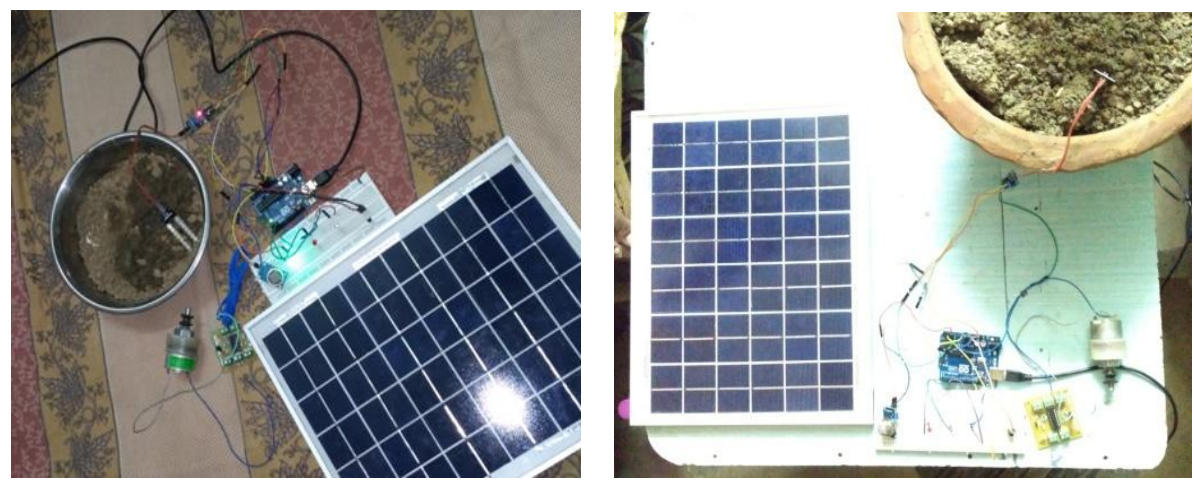

FIG 11. SNAPSHOTS OF AUTOMATIC SOIL MOISTURE MONITORING SYSTEM

\section{REFERENCES}

[1] K.S.S. Prasad, Nitesh Kumar, Nitish Kumar Sinha and Palash Kumar Saha "Water-Saving Irrigation System Based on Automatic Control by Using GSM Technology" Middle-East Journal of Scientific Research 12 (12): 1824-1827, 2012.

[2] N.R. Mohantyandc.Ypatil, "Wireless Sensor And Network Design For Greenhouse Automation", International Journal Of Engineering Technology,Volume3,Issue2,August 2013

[3] "Irrigation System Controllers", SSAGE22, Agricultural and Biological Engineering Department, Florida Cooperative Extension Service, Institute of Food and Agricultural Sciences, University of Florida. Available: http://edis.ifas.ufl.edu

[4] Sanjukumar, R.V.Krishnaiah “ Advance Technique for Soil Moisture Content Based Automatic Motor Pumping for Agriculture Land Purpose" Volume 04, Article 09149; September 2013.

[5] Khaled Reza, S.M., Shah Ahsanuzzaman Md. Tariq, S.M. Mohsin Reza (2010), 'Microcontroller Based Automated Water Level Sensing and Controlling: Design and Implementation Issue'. Proceedings of the World Congress on Engineering and Computer Science, pp 220-224.

[6] WWW.PROJECTSOF8051.COM

[7] WWW.ARDUINO.CC

[8] WWW.CIRCUITSTODAY.COM 